\title{
USO DE CENAS VIDEOGRÁFICAS PARA AVALIAÇÃO DA FLORESTA URBANA
}

Francisco Martins de Almeida Rollo ${ }^{1}$, Demóstenes Ferreira da Silva Filho ${ }^{2}$, Hilton Thadeu Zarate do Couto $^{3}$, Jefferson Lordello Polizel ${ }^{4}$

\section{RESUMO}

A videografia multiespectral de alta resolução é uma ferramenta de extrema importância dentro de projetos de sensoriamento remoto. Estudos recentes mostraram resultados satisfatórios para sua utilização em estudos sobre o tecido urbano e florestas urbanas, validando sua utilização em projetos de planejamento urbano. Como o tecido urbano está em constante mudança, novos inventários precisam ser conduzidos para a atualização dos dados. Este trabalho mediu a confiabilidade dos dados gerados por classificação supervisionada de cenas videográficas de diferentes bairros de Piracicaba - SP, comparando os resultados obtidos com a classificação supervisionada da área total desses mesmos bairros. Os resultados estatísticos provaram que o uso de cenas videográficas para a realização de classificação supervisionada é válido, possibilitando a realização de estudos de baixo custo de maneira rápida e eficiente.

Palavras-chave: sensoriamento remoto, videografia aérea multiespectral, floresta urbana, processamento de imagens, cenas videográficas.

\footnotetext{
${ }^{1}$.Gestor Ambiental, mestrando USP/ESALQ - Piracicaba - SP, francisco.rollo@yahoo.com.br

2. Engenheiro Agrônomo - Professor Doutor USP/ESALQ - Piracicaba - SP, dfsilva@esalq.usp.br

3. Engenheiro Agrônomo - Professor Doutor USP/ESALQ - Piracicaba - SP, htzcouto@esalq.usp.br

${ }^{4}$..Analista de Sistemas - mestrando FFLECH, Funcionário LMQ USP/ESALQ - Piracicaba - SP, jlpolize@esalq.usp.br
} 


\title{
USE OF VIDEOGRAPHIC SCENES FOR THE URBAN FOREST EVALUATION
}

\begin{abstract}
High resolution multispectral videography is a very important tool in remote sensing projects. Recent research shows satisfactory results to its use in urban fabric and urban forests studies, validating its application in urban planning projects. Because the urban fabric is in constant change, new inventories must be made in order to update the data. This paper evaluated the usefulness of the results generated by supervised classification of the videographic scenes of different neighborhood of Piracicaba-SP, Brazil, comparing the results obtained with the supervised classification of the total area of the same neighborhoods. The statistical results proved that the use of scenes for supervised classifications is useful, enabling the accomplishment of faster, more efficient and less costly studies.
\end{abstract}

Key-words: remote sensing, airborne multispectral videography, urban forest, image processing, videographic scenes. 


\section{INTRODUÇÃO}

Devido ao crescente número de pessoas vivendo em núcleos urbanos e à importância de compreendê-los, atualmente as diferentes técnicas de sensoriamento remoto são de grande valia para estudo e qualificação de áreas urbanas, bem como para a rápida e correta tomada de decisão por parte dos administradores públicos.

Dentre as técnicas de sensoriamento remoto existentes, a videografia aérea multiespectral de alta resolução permite o levantamento de um grande volume de informações em curto espaço de tempo e a custos relativamente baixos quando comparados aos custos de outras técnicas.

Essa técnica vem sendo largamente utilizada em países como os Estados Unidos da América. No Brasil, é pouco difundida, mas de uso crescente em função de sua ampla variedade de aplicações, que vão desde o planejamento urbano até a detecção de impactos ambientais.

Segundo MOREIRA (2003), um dos primeiros estudos com o emprego de videografia no país foi realizado em Manaus em 1997, com o objetivo de verificar a capacidade de obtenção de dados biofísicos da floresta para calibração de dados orbitais. Nesta mesma época, estudos com videografia foram realizados em Piracicaba, interior do Estado de São Paulo em pesquisas voltadas à agricultura de precisão e aplicações florestais (COUTO et al., 2000).

Todavia, até o presente momento, existem poucos trabalhos com a aplicação de videografia em áreas urbanas no Brasil e as experiências são escassas em outros países. SACAMANO et al. (1995) desenvolveram testes entre diversos tipos de fotografias aéreas e imagens de videografias analógicas e digitais para a localidade de Oak Park, Illinois com a intenção de identificar os meios mais econômicos e precisos para a descrição e quantificação da floresta urbana local.

Estudos sobre a floresta urbana são extremamente relevantes devido sua grande importância na qualidade ambiental e estética dos centros urbanos. PAIVA \& GONÇALVES (2002) ressaltam que a cobertura vegetal do solo urbano está relacionada com diversos aspectos ambientais, entre eles a com a retenção e estabilização do solo, prevenção contra a erosão, pois tem efeitos amortecedores de chuva e favorecimento à infiltração de água, proporcionando menor escoamento superficial, produção de sombra às margens dos cursos d'água, mantendo a água na temperatura adequada às diversas espécies de peixes e outros organismos aquáticos, além de influir no clima, integrar o ciclo hidrológico, oxigenar o ambiente, fornecer matéria prima e alimentos e integrar a paisagem urbana. Segundo os autores a floresta urbana ainda constitui ambiente natural para diversas espécies de animais, dispersam e absorvem poluentes atmosféricos além de minorar os ruídos urbanos 
Um dos aspectos mais importantes da floresta urbana é sua capacidade de remoção de poluentes do ambiente. A ação purificadora das árvores ocorre em função da fixação de particulados; da depuração bacteriana e da captação de gases tóxicos. Ruas bem arborizadas podem filtrar grande parte da poeira em suspensão no ar (GREY; DENEKE, 1931). Simulações realizadas nos Estados Unidos por NOWAK et al (2000) avaliaram a remoção de poluentes pelas árvores urbanas. Em Nova York, o índice obtido foi de uma remoção de $13,7 \mathrm{~g}$ de poluentes por $\mathrm{m}^{2}$ de copa arbórea. O mesmo estudo ressalta a importância da floresta urbana na diminuição da concentração de $\mathrm{CO}_{2}$ do ar por meio da incorporação do carbono em seu crescimento. Segundo o autor, árvores de grande porte (acima de $77 \mathrm{~cm}$ de diâmetro na altura do peito - DAP) acumulam cerca de 1000 vezes mais carbono do que árvores de pequeno porte (abaixo de $7 \mathrm{~cm}$ de DAP).

Outro benefício ocasionado pela floresta urbana diz respeito ao conforto térmico. MASMOUDI \& MAZOUZ (2004) concluíram por meio de modelagens que as árvores presentes no tecido urbano interceptam de maneira significativa a energia proveniente do sol, implicando em superfícies menos aquecidas e temperaturas mais amenas nos locais onde são encontradas. SHASHUA-BAR \& HOFFMAN (2003) ressaltam a importância da arborização na mitigação de ilhas de calor por meio do sombreamento, filtrando a radiação solar e pelo papel na influência sobre as correntes de vento e massas de ar. Diversos estudos foram realizados mostrando o benefício que a arborização traz em relação ao conforto térmico e atenuação de temperaturas. PICOT (2004) estudou o potencial de utilização da arborização sobre o conforto térmico em uma praça na Itália, mostrando a efetividade do uso de arborização para tal fim. GÓMEZ et al (2004) estudaram a vegetação no município de Valência, Espanha e contatam que a vegetação é muito importante no papel de controlar o balanço energético da cidade, afetando o albedo e a quantidade de radiação solar que atinge as superfícies urbanas. WILLMERS (1991) estudou a vegetação do município de Hannover, indicando que o planejamento de áreas urbanas com incremento da vegetação propiciaria temperaturas mais amenas e maior umidade relativa do ar.

SILVA FILHO (2004) avaliou a floresta urbana de nove bairros do município de Piracicaba-SP por meio do emprego de videografia. Neste trabalho, foi possível utilizar a videografia de alta resolução para a identificação e quantificação não apenas da floresta urbana, mas também para a avaliação do tecido urbano como um todo, composto por outros sistemas como o viário, edificações, pavimentações e demais tipos de coberturas urbanas. Para tal, foi utilizado o método de classificação supervisionada.

A classificação supervisionada utiliza algoritmos cujo reconhecimento dos padrões espectrais na imagem se faz com base numa amostra de área de treinamento (treinador), que é fornecida ao sistema de classificação pelo analista. 
Por meio das classes identificadas no treinador, são determinados valores centrais e a variabilidade em cada banda e cada classe do treinador. Esta informação permite ao processo determinar a probabilidade de uma dada célula de um pacote de bandas pertencer a uma determinada classe do treinador. A probabilidade depende da distância do valor da célula para o valor central da classe, e o tamanho e forma das classes no espaço espectral (SILVA FILHO 2004).

Por meio da construção de uma matriz de erro é possível utilizar-se de técnicas de análise multivariada discreta para determinar a concordância da classificação (mapeamento temático) com a verdade de campo. A grande vantagem dessa estatística é a inclusão no coeficiente Kappa de todos os elementos da matriz de erro e não somente os elementos da diagonal principal, como no caso da exatidão geral (CONGALTON, 2001; MOREIRA, 2003).

Vale a pena destacar que os estudos de sensoriamento remoto realizados em áreas urbanas necessitam de atualizações, pois o tecido urbano é dinâmico. Casas são construídas e demolidas, ruas são pavimentadas, edifícios são erguidos, fazendo com que os dados obtidos estejam, em pouco tempo, defasados. Constantes inventários implicam em investimentos financeiros, o que pode vir a ser um empecilho para que tais atualizações sejam realizadas com regularidade.

Neste contexto, esse trabalho visa testar a confiabilidade de resultados gerados pela classificação supervisionada de cena única de quatorze bairros do Município de PiracicabaSP, comparando os resultados obtidos com a classificação supervisionada realizada na área total destes mesmos bairros, após mosaico, subsidiando o desenvolvimento de alternativas para quantificação e atualização rápida e de baixo custo que poderá permitir estudos aprofundados e precisos sobre a cobertura vegetal e o tecido urbano.

\section{MATERIAIS E MÉTODOS}

\section{Localização Geográfica e Clima do Município}

O Município de Piracicaba situa-se entre as coordenadas geográficas $22^{\circ} 42^{\prime}$ de latitude Sul e 47038' de longitude Oeste de Greenwich. Em linha reta, dista $138 \mathrm{Km} \mathrm{da}$ capital do Estado, São Paulo e está a 540 metros de altitude (IBGE, 2002).

O clima é subtropical úmido com estiagem no inverno, com temperatura média do mês mais quente superior a $22^{\circ} \mathrm{C}$ e do mês mais frio inferior a $18^{\circ} \mathrm{C}$.

\section{Descrição do Método}

Como método de trabalho, executou-se, a coleta de dados, por meio de videografia aérea de alvos intra-urbanos. Os bairros videografados para este presente estudo foram Morato, Paulicéia, Cidade Jardim, Jardim Monumento, São Dimas, São Judas, Vila 
Rezende, Nhoquim, Castelinho, Vila Independência, Cidade Alta, Centro, Piracicamirim e Vila Monteiro.

Para montagem do sistema foi utilizada uma câmera digital multiespectral colorida, com resolução de imagem de 1384 x 1036 pixels, apta para capturar imagens na faixa do espectro visível e do infravermelho próximo (400-1100 nm). Para a fixação do equipamento foi utilizado suporte em abertura localizada no piso de um avião monomotor. Os vôos foram realizados nos dias quatro e seis de agosto de 2005 entre 11:30 e 14:15 e 11:30 e 13:31, respectivamente. Ambos foram realizados a aproximadamente 2800 metros de altitude.

A câmera foi conectada a um monitor para que a visualização dos alvos filmados, possibilitando desta forma a detecção e correção de problemas com a rota do avião ou com a regulagem dos equipamentos. As imagens foram digitalizadas em cenas para computador assim que obtidas, ou seja, em tempo real.

Para o georreferenciamento e correção geométrica das imagens foram coletadas as coordenadas de pontos de apoio no terreno, por meio de um receptor GPS topográfico. Os dados coletados foram corrigidos diferencialmente, em pós-processamento, pelos dados de uma estação base. Para o georreferenciamento e correção geométrica das imagens foram inseridas coordenadas geográficas obtidas do GPS e, em seguida, procedeu-se à escolha das melhores cenas, buscando - se a abrangência do espaço intra-urbano de cada bairro.

Análises de pixel foram elaboradas para determinação dos valores dos níveis de cinza (NC). Os valores de NC foram obtidos para as faixas "R" (infravermelho próximo), "G" (vermelho) e "B" (parte do azul e todo o verde), utilizando-se o programa de geoprocessamento TNT Mips 7.2, objetivando um erro mínimo na classificação e mensuração das áreas intra-urbanas e seus componentes.

\section{Elaboração de Classificação Automática Supervisionada}

Utilizou-se para a classificação supervisionada das cenas o algoritmo da máxima verossimilhança. Como base geral para classificação supervisionada utilizou-se ortofoto digitalizada dos bairros, fornecida pela Prefeitura de Piracicaba e elaborada no ano de 2000. Esta ortofoto possui alta qualidade do ponto de vista fotogramétrico e ótima resolução espacial, possibilitando a identificação visual dos alvos intra-urbanos para a confecção dos treinadores e auditores da classificação automática supervisionada. Essa imagem serviu também para a medição da área dos bairros imageados, bem como para a determinação de seus limites espaciais. Foi utilizado como base geral para a classificação também o software Google Earth. Para dirimir dúvidas de alguns alvos foram feitas averiguações nos locais imageados para conferência da classificação.

Para avaliar estatisticamente a exatidão do mapeamento temático utilizou-se a estatística Kappa extraída de matriz de erro obtida pelo programa de geoprocessamento 
TNT Mips 7.2, conforme descrito em LANDIS e KOCH (1977) e MOREIRA (2003). A estatística Kappa pode ser obtida por meio das equações:

$$
\begin{aligned}
& K=\frac{P_{0}-P_{c}}{1-P c}(1) \\
& P O=\frac{\sum_{i=1}^{M} n_{i i}}{N}(2) \\
& P C=\frac{\sum_{i=1}^{M} n_{i+} n_{i+}}{N^{2}}(3)
\end{aligned}
$$

Sendo Po a exatidão geral; Pc, a proporção de unidades que concordam por casualidade; $\mathrm{M}$, o número de classes presentes na matriz de erro; nij, o número de observações na linha i e coluna j; $n i+e n+i$, os totais marginais da linha i e da coluna $j$, respectivamente; e $\mathrm{N}$, o número total de unidades amostrais contempladas pela matriz. $\mathrm{O}$ valor da estatística Kappa, determinado por meio da equação (1), é comparado em classes de acurácia sendo que de $80 \%$ a $100 \%$ a classificação é reconhecida como excelente (LANDIS e KOCH, 1977).

Neste processo de classificação supervisionada, não foram computadas na classificação áreas identificadas como rios, matas ciliares e vazios urbanos compostos de solo exposto, vegetação e relvado, por não serem consideradas áreas componentes do tecido urbano propriamente dito. Em alguns bairros não foram utilizadas todas as classes devido às especificidades de cobertura de cada bairro.

\section{Escolha e Classificação de Cena}

Para que fosse possível comparar os resultados obtidos na classificação supervisionada dos bairros analisados neste trabalho com a classificação de cena única de cada bairro, foi determinado que a cena única (aproximadamente $700 \times 1000$ metros) a ser analisada deveria abranger as partes mais centrais de cada bairro.

Após realizada a escolha da cena a ser analisada, foi aplicado o mesmo procedimento de classificação supervisionada adotado para a classificação dos bairros, permitindo desta forma uma comparação direta entre os resultados obtidos. 


\section{Forma de análise dos dados temáticos}

Os dados obtidos com a classificação supervisionada das cenas foram comparados com os dados obtidos com a classificação supervisionada (Figura 1) nos bairros e analisados por meio dos testes estatísticos $\mathrm{R}$ e t, além de obtenção de gráfico de dispersão, visando desta maneira aprimorar a análise dos resultados obtidos.
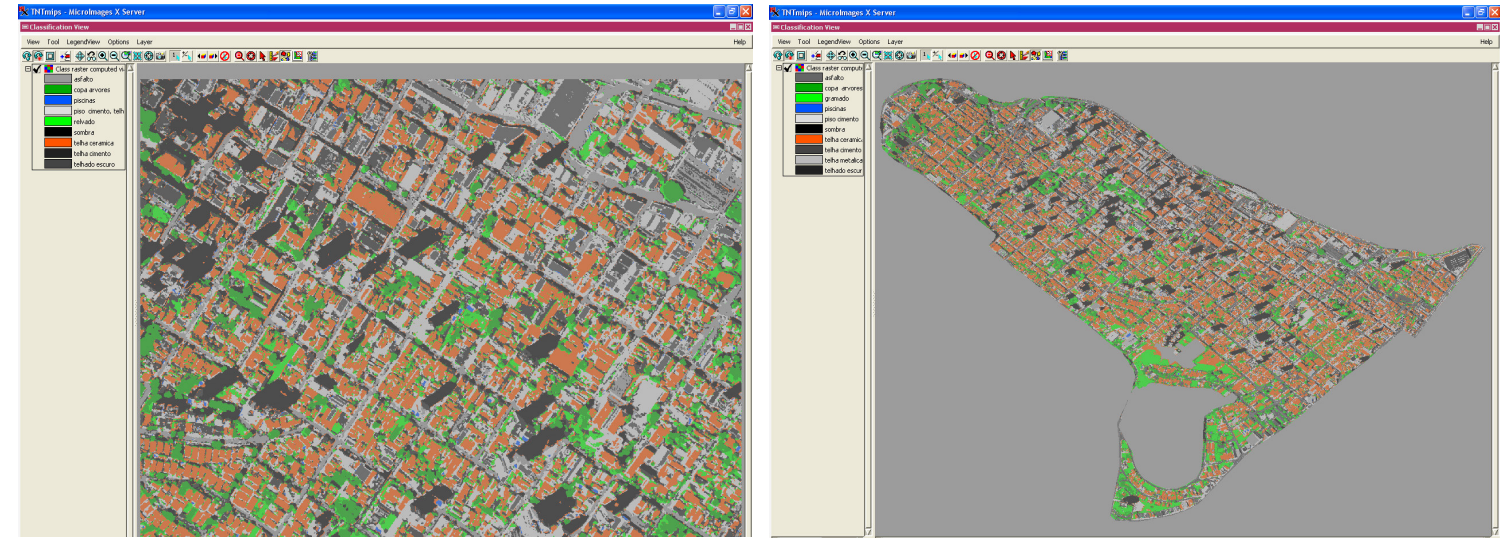

Figura 1. Classificação supervisionada da cena e mosaico para o bairro centro.

Foram analisadas as classes de cobertura Copa de Árvores/Arbustos, Gramíneas/Herbáceas, além dos índices propostos por SILVA FILHO (2004) Espaço Livre Impermeável, resultante da combinação das classes Asfalto e Piso Cimento, Espaço Livre Permeável, resultante da combinação das classes Solo e Terreno Roçado, Espaço Livre Vegetado, resultante da combinação das classes Copa de Árvores/Arbustos e Gramíneas/Herbáceas e Espaço Construído, resultante da combinação das classes Cobertura Clara, Telha Cerâmica, Telha Escura, Telha Azul e Telha Cimento. Foi analisado também o Índice de Floresta Urbana, um indicador para valorização de espaços arborizados relacionados com os outros constituintes do meio, tais como ruas, calçadas, quadras, casas e edifícios (SILVA FILHO, 2004).

O Índice de Floresta Urbana é obtido por meio do cálculo:

$$
I F U=P A I+P A C
$$

Sendo que os índices PAI (proporção entre Espaço Arborizado e Espaço Livre Impermeável) e PAC (proporção entre Espaço Arborizado e Espaço Construído) podem ser obtidos por meio das seguintes fórmulas:

$$
\begin{aligned}
& P A I=\frac{E L A}{(E L A+E L I)} \\
& P A C=\frac{E L A}{(E L A+E C)}
\end{aligned}
$$


Onde ELA representa o Espaço Livre Arborizado, ELI o Espaço Livre Impermeabilizado e EC o Espaço Construído. O IFU pode variar entre os valores zero e dois, sendo que quanto maior o valor do índice, maior é a porcentagem de cobertura vegetal em relação aos demais constituintes do mesmo.

\section{RESULTADOS E DISCUSSÃO}

A Tabela 1 apresenta as porcentagens de cobertura obtidas por meio da classificação supervisionada dos bairros. As porcentagens obtidas por meio da classificação supervisionada das cenas únicas estão expostas na Tabela 2. 
Tabela 1. Porcentagens obtidas por meio da classificação supervisionada dos bairros, apresentados na seguinte ordem: Cidade Jardim (C J), Vila Monteiro (V M), Morato (M), São Dimas (S D), Vila Independência (V I), Paulicéia (PA), Nhoquim (N), Cidade Alta (Cl. A), São Judas (S J), Vila Rezende (V R), Jardim Monumento (J M), Centro (C), Piracicamirim (PI) e Castelinho (CA).

\begin{tabular}{|c|c|c|c|c|c|c|c|c|c|c|c|c|c|c|c|}
\hline Classes de cobertura (\%) & Variáveis espaciais & C J & V M & $\mathbf{M}$ & S D & V I & PA & $\mathbf{N}$ & Cl. A & S J & V R & J M & C & PI & CA \\
\hline Água rio/lago & Espaço d'água & 0 & 0 & 0,13 & 0 & 0 & 0 & 0 & 0 & 0 & 0 & 2,82 & 0 & 0 & 0 \\
\hline Piscina & Espaço d’água & 0,19 & 1,23 & 0,25 & 1,22 & 0,31 & 0 & 0,89 & 0,26 & 0,25 & 0,64 & 1,09 & 0,32 & 0,02 & 0,42 \\
\hline Total de Espaço d'água & & 0,19 & 1,23 & 0,38 & 1,22 & 0,31 & 0 & 0,89 & 0,26 & 0,25 & 0,64 & 3,91 & 0,32 & 0,02 & 0,42 \\
\hline Asfalto & Espaço Livre Impermeável & 6,8 & 7,22 & 10,67 & 7,1 & 10,22 & 9,92 & 8,84 & 10,85 & 8,9 & 11,57 & 11,52 & 7,84 & 13,62 & 11,46 \\
\hline Piso cimento & Espaço Livre Impermeável & 0 & 9,91 & 8,13 & 6,7 & 2,5 & 13,98 & 7 & 1,81 & 20,03 & 6,76 & 13,22 & 15,88 & 13,90 & 8,3 \\
\hline \multicolumn{2}{|c|}{ Total de Espaço Livre Impermeável = ELI } & 6,8 & 17,13 & 18,8 & 13,8 & 12,72 & 23,9 & 15,84 & 12,66 & 28,93 & 18,33 & 24,74 & 23,72 & 27,52 & 19,76 \\
\hline Copa de árvores/arbustos & Espaço Livre Arborizado & 14,66 & 19,00 & 15,11 & 12,85 & 11,2 & 9,41 & 8,42 & 7,31 & 9,58 & 7,95 & 7,14 & 7,00 & 6,95 & 4,03 \\
\hline Gramíneas / herbáceas & Espaço Livre Herbáceo & 12,08 & 11,49 & 21,19 & 7,21 & 11 & 11,07 & 11,44 & 3,17 & 12 & 7,87 & 9,49 & 8,08 & 18,05 & 13,25 \\
\hline \multicolumn{2}{|c|}{ Total de Espaço Livre Vegetado = ELV } & 26,74 & 30,49 & 36,3 & 20,06 & 22,2 & 20,48 & 19,86 & 10,48 & 21,58 & 15,82 & 16,63 & 15,08 & 25,00 & 17,28 \\
\hline Solo & Espaço Livre Permeável & 0,94 & 4,10 & 11,47 & 8,55 & 4,38 & 14,08 & 0 & 0,09 & 4,11 & 0 & 15,49 & 0 & 5,36 & 7,39 \\
\hline Terreno roçado & Espaço Livre Permeável & 0 & 0 & 0 & 0 & 0 & 0 & 0 & 0 & 0 & 0 & 0 & 0 & 0 & 0 \\
\hline \multicolumn{2}{|c|}{ Total de Espaço Livre Permeável = ELP } & 0,94 & 4,10 & 11,47 & 8,55 & 4,38 & 14,08 & 0 & 0,09 & 4,11 & 0 & 15,49 & 0 & 5,36 & 7,39 \\
\hline Cobertura clara & Espaço construído & 1,67 & 0,44 & 1,68 & 4,07 & 6,34 & 4,52 & 5,61 & 16,27 & 2,32 & 7,76 & 1,17 & 3,50 & 0,54 & 3,78 \\
\hline Telha cerâmica & Espaço construído & 24,14 & 25,58 & 6,28 & 24,55 & 37,13 & 17,73 & 25,41 & 33,72 & 20,86 & 24,72 & 24,01 & 27,15 & 25,44 & 28,55 \\
\hline Telha escura & Espaço construído & 9,2 & 9,46 & 17,95 & 0 & 7,81 & 6,3 & 23,73 & 18,29 & 13,73 & 20,94 & 5,1 & 2,96 & 9,49 & 3,06 \\
\hline Telha azul & Espaço construído & 0 & 0 & 0 & 0 & 0 & 0 & 0 & 0 & 0 & 0 & 0 & 0 & 0 & 0 \\
\hline Telha cimento & Espaço construído & 21,24 & 4,31 & 1,02 & 17,97 & 1,9 & 9,41 & 2,38 & 1,81 & 0 & 0 & 0 & 17,18 & 2,95 & 13,93 \\
\hline \multicolumn{2}{|c|}{ Total de Espaço Construído = EC } & 56,25 & 39,79 & 26,93 & 46,59 & 53,18 & 37,96 & 57,13 & 70,09 & 36,91 & 53,42 & 30,28 & 50,79 & 38,42 & 49,32 \\
\hline Sombra & Espaço sombreado & 9,09 & 7,25 & 6,11 & 9,79 & 7,21 & 3,57 & 6,27 & 5,02 & 8,22 & 11,8 & 8,95 & 10,08 & 3,68 & 5,83 \\
\hline TOTAL & & 100 & 100 & 100 & 100 & 100 & 100 & 100 & 100 & 100 & 100 & 100 & 100 & 100 & 100 \\
\hline Índice Kappa (\%) & & 91,42 & 86,43 & 89,16 & 87,51 & 97,68 & 82,22 & 85,04 & 86,10 & 89,04 & 90,15 & 88,3 & 85,56 & 86,61 & 85,77 \\
\hline PAC & & 0,2 & 0,32 & 0,36 & 0,21 & 0,17 & 0,2 & 0,13 & 0,09 & 0,2 & 0,13 & 0,19 & 0,12 & 0,15 & 0,08 \\
\hline PAI & & 0,68 & 0,53 & 0,44 & 0,48 & 0,47 & 0,28 & 0,34 & 0,37 & 0,25 & 0,3 & 0,22 & 0,23 & 0,20 & 0,17 \\
\hline IFU & & 0,88 & 0,85 & 0,80 & 0,69 & 0,64 & 0,48 & 0,47 & 0,46 & 0,45 & 0,43 & 0,41 & 0,35 & 0,35 & 0,24 \\
\hline
\end{tabular}


Tabela 2. Porcentagens obtidas por meio da classificação supervisionada das cenas únicas, apresentadas na seguinte ordem: Cidade Jardim (C J), Vila Monteiro (V M), Morato (M), São Dimas (S D), Vila Independência (V I), Paulicéia (PA), Nhoquim (N), Cidade Alta (Cl. A), São Judas (S J), Vila Rezende (V R), Jardim Monumento (J M), Centro (C), Piracicamirim (PI) e Castelinho (CA).

\begin{tabular}{|c|c|c|c|c|c|c|c|c|c|c|c|c|c|c|c|}
\hline Classes de cobertura (\%) & Variáveis espaciais & C J & V M & M & S D & V I & PA & $\mathbf{N}$ & Cl. A & S J & V R & J M & C & PI & CA \\
\hline Água rio/lago & Espaço d’água & 0 & 0 & 0,25 & 0 & 0 & 0 & 0 & 0 & 0 & 0 & 3,48 & 0 & 0 & 0 \\
\hline Piscina & Espaço d'água & 0,3 & 1,14 & 1,12 & 0,92 & 0,66 & 0 & 0,06 & 1,41 & 1,46 & 0,14 & 1,8 & 0,41 & 0,01 & 2,04 \\
\hline Total de Espaço d'água & & 0,3 & 1,14 & 1,37 & 0,92 & 0,66 & 0 & 0,06 & 1,41 & 1,46 & 0,14 & 5,28 & 0,41 & 0,01 & 2,04 \\
\hline Asfalto & Espaço Livre Impermeável & 5,82 & 7,48 & 7,33 & 6,89 & 8,26 & 8,44 & 7,27 & 9,00 & 9,81 & 7,45 & 11,2 & 9,99 & 12,72 & 14,46 \\
\hline Piso cimento & Espaço Livre Impermeável & 0 & 10,62 & 11,39 & 5,84 & 2,15 & 8,31 & 9,68 & 3,52 & 11,52 & 7,14 & 9,23 & 18,61 & 20,72 & 7,07 \\
\hline \multicolumn{2}{|c|}{ Total de Espaço Livre Impermeável = ELI } & 5,82 & 18,10 & 18,72 & 12,73 & 10,41 & 16,75 & 16,95 & 12,52 & 21,33 & 14,59 & 20,43 & 28,60 & 33,44 & 21,53 \\
\hline Copa de árvores/arbustos & Espaço Livre Arborizado & 13,79 & 19,49 & 15,43 & 8,63 & 10,95 & 7,25 & 9,39 & 6,41 & 7,23 & 4,22 & 6,84 & 6,76 & 6,20 & 4,67 \\
\hline Gramíneas / herbáceas & Espaço Livre Herbáceo & 11,48 & 4,15 & 26,33 & 9,24 & 5,1 & 11,96 & 11,48 & 6,34 & 7,21 & 16,12 & 11,78 & 6,79 & 10,85 & 16,64 \\
\hline \multicolumn{2}{|c|}{ Total de Espaço Livre Vegetado $=E L V$} & 25,27 & 23,64 & 41,76 & 17,87 & 16,05 & 19,21 & 20,87 & 12,75 & 14,44 & 20,34 & 18,62 & 13,55 & 17,05 & 21,31 \\
\hline Solo & Espaço Livre Permeável & 0 & 1,13 & 8,23 & 6,41 & 0 & 14,08 & 0 & 0,00 & 9,7 & 0 & 21,8 & 0,00 & 0,00 & 11,55 \\
\hline Terreno roçado & Espaço Livre Permeável & 0 & 0,00 & 0 & 0 & 0 & 0 & 0 & 0,00 & 0 & 0 & 0 & 0,00 & 0,00 & 0 \\
\hline \multicolumn{2}{|c|}{ Total de Espaço Livre Permeável $=$ ELP } & 0 & 1,13 & 8,23 & 6,41 & 0 & 14,08 & 0 & 0 & 9,7 & 0 & 21,8 & 0 & 0 & 11,55 \\
\hline Cobertura clara & Espaço construído & 5,79 & 0,46 & 0,31 & 10,26 & 0,78 & 2,35 & 4,57 & 6,57 & 3,61 & 9,48 & 1,39 & 2,53 & 1,31 & 2,63 \\
\hline Telha cerâmica & Espaço construído & 24,33 & 33,20 & 11,17 & 26,19 & 41,09 & 14,14 & 27,04 & 38,29 & 26,31 & 25,87 & 16,15 & 23,53 & 31,04 & 20,13 \\
\hline Telha escura & Espaço construído & 9,88 & 9,69 & 10,2 & 0 & 15,35 & 18,47 & 19,76 & 16,08 & 13,76 & 16,31 & 7,08 & 4,05 & 8,48 & 3,75 \\
\hline Telha azul & Espaço construído & 0 & 0 & 0 & 0 & 0 & 0 & 0 & 0 & 0 & 0 & 0 & 0 & 0 & 0 \\
\hline Telha cimento & Espaço construído & 16,92 & 4,65 & 0 & 14,09 & 2,15 & 5,69 & 3,17 & 3,19 & 0 & 0 & 0 & 15,53 & 3,66 & 12,22 \\
\hline \multicolumn{2}{|c|}{ Total de Espaço Construído = EC } & 56,92 & 47,54 & 21,68 & 50,54 & 59,37 & 40,65 & 54,54 & 64,13 & 43,68 & 51,66 & 24,62 & 45,64 & 44,49 & 38,73 \\
\hline Sombra & Espaço sombreado & 11,68 & 7,95 & 8,24 & 11,54 & 6,15 & 9,31 & 7,59 & 9,21 & 9,37 & 13,25 & 9,24 & 11,74 & 5,01 & 4,84 \\
\hline TOTAL & & 100 & 100 & 100 & 100 & 100 & 100 & 100 & 100,00 & 100 & 100 & 100 & 100 & 100 & 100 \\
\hline Índice Kappa (\%) & & 89,39 & 89,42 & 87,78 & 85,28 & 88,99 & 83,28 & 91,36 & 85,39 & 80,8 & 85,61 & 86,21 & 88,34 & 91,95 & 84,61 \\
\hline PAC & & 0,19 & 0,29 & 0,41 & 0,15 & 0,16 & 0,15 & 0,15 & 0,09 & 0,14 & 0,07 & 0,22 & 0,13 & 0,12 & 0,11 \\
\hline PAI & & 0,7 & 0,52 & 0,45 & 0,4 & 0,51 & 0,3 & 0,35 & 0,34 & 0,25 & 0,22 & 0,25 & 0,19 & 0,16 & 0,18 \\
\hline IFU & & 0,89 & 0,81 & 0,86 & 0,55 & 0,67 & 0,45 & 0,5 & 0,43 & 0,39 & 0,29 & 0,47 & 0,32 & 0,28 & 0,29 \\
\hline
\end{tabular}


Resultados estatísticos da análise de regressão linear simples apresentaram valores de coeficientes de determinação $\left(R^{2}\right)$ e resultados dos testes de significância (t) que apontam para a grande confiabilidade dos resultados gerados pela classificação supervisionada das cenas únicas. Os valores do coeficiente de determinação para a comparação entre os Índices de Floresta Urbana, porcentagem de cobertura de árvores e arbustos, Espaço Construído e Espaço Livre Impermeável estão apresentados nas Figuras 2, 3, 4 e 5.

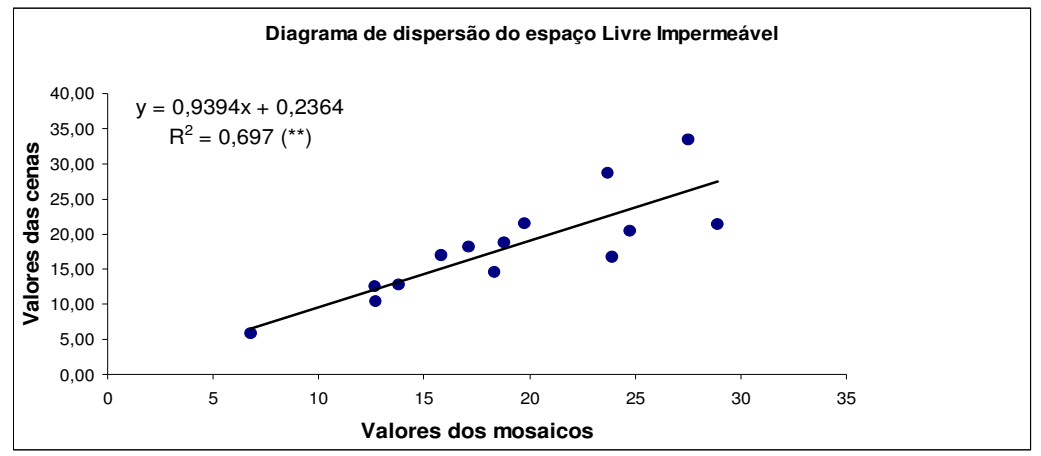

Figura 2 Diagrama de dispersão do espaço livre impermeável

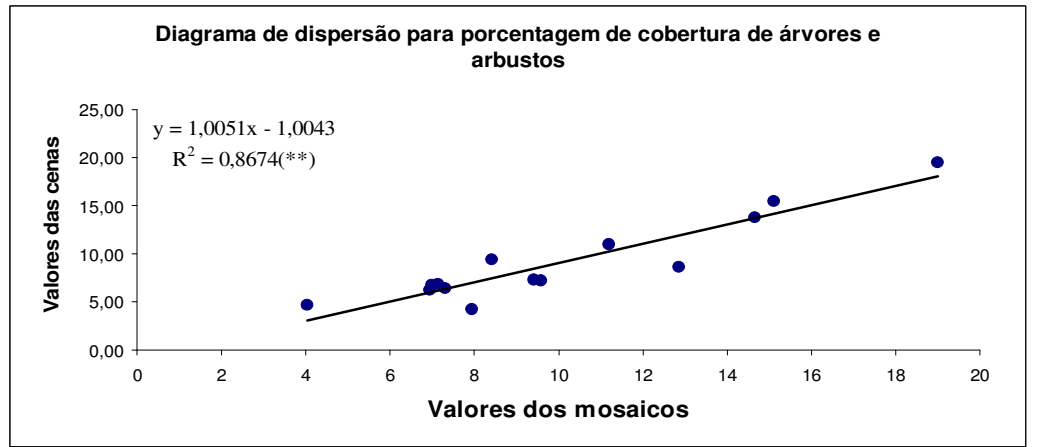

Figura 3 Diagrama de dispersão para a porcentagem de cobertura de árvores e arbustos

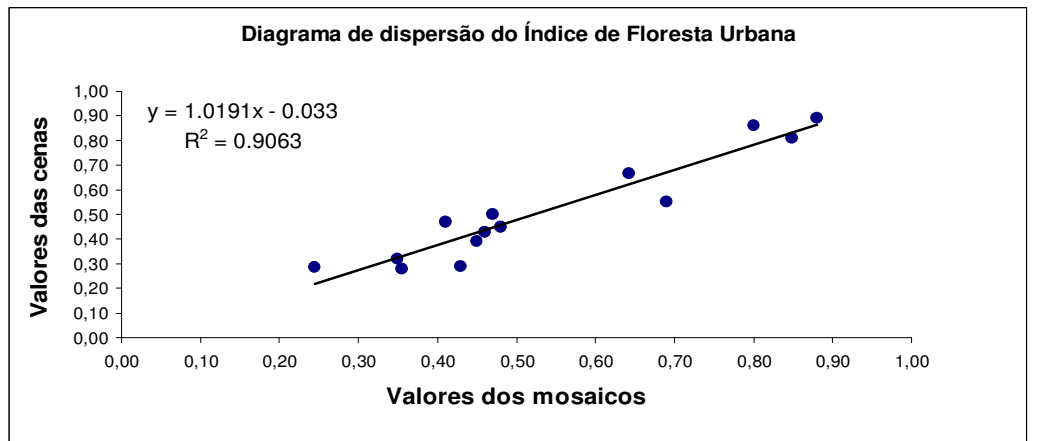

Figura 4 Diagrama de dispersão do índice de floresta urbana 


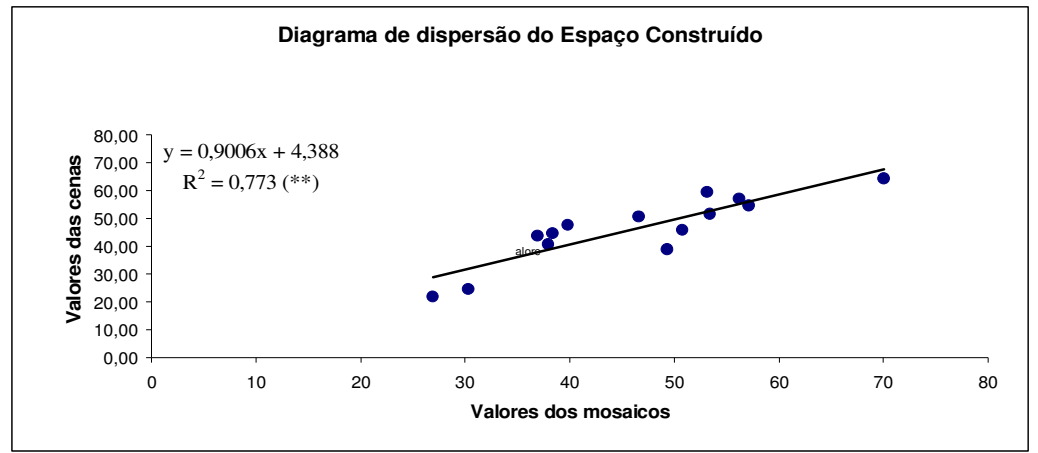

Figura 5 Diagrama de dispersão do espaço construído

Figuras 2, 3, 4 e 5. Diagramas de dispersão e equações de regressão. Nos eixos $X$ estão contidos os dados referentes aos mosaicos, enquanto no eixo $Y$ estão contidos os dados referentes às cenas. Os asteriscos indicam que os valores de $\mathrm{R}^{2}$ são significativos pelo teste t a $1 \%\left({ }^{* *}\right)$.

Os resultados obtidos na quantificação de cobertura dos bairros foram muito semelhantes aos obtidos na quantificação das cenas únicas. A classe que apresentou resultados mais discrepantes foi a classe Gramíneas e Herbáceas. Tal resultado pode ser explicado pelo fato deste tipo de cobertura encontrar-se concentrado em pontos específicos dentro do tecido urbano, como em terrenos sem edificações, campos de futebol e outras manchas isoladas. Todas as outras classes quantificadas apresentam distribuição espacial uniforme por todo o tecido urbano.

\section{CONCLUSÕES}

Os resultados obtidos por meio das análises estatísticas comprovam que a utilização de cena única para realização de classificação supervisionada resulta na obtenção de dados altamente confiáveis, que podem gerar estimativas confiáveis para a totalidade dos bairros.

Devido à confiabilidade nos dados gerados, a classificação supervisionada de cenas únicas apresenta-se como uma alternativa rápida e de baixo custo para a elaboração e atualização de estudos sobre tecidos urbanos.

A interpretação dos dados permite apontar diferenças marcantes em relação à cobertura arbórea dos bairros analisados. Embora todos os bairros analisados tenham apresentado IFU aquém do desejado (SILVA FILHO 2005), foram identificados valores muito discrepantes, oscilando entre 0,24 na análise de cena do bairro Castelinho e 0,88 na análise de cena do bairro Cidade Jardim. Diretrizes de políticas públicas deveriam priorizar o incremento da floresta urbana nos bairros onde os IFU encontrados foram menores, 
enquanto nos bairros com índices mais elevados, as diretrizes deveriam ser adotadas com o objetivo de conservar, diversificar e propiciar um bom manejo das árvores.

Foi possível observar também nos bairros analisados que todos apresentam, em maior ou menor grau, características comumente encontradas em bairros densamente ocupados, com altas porcentagens de espaços impermeáveis e espaços construídos, em detrimento aos espaços livres permeáveis, vegetados e conseqüentemente à vegetação urbana. Medidas devem ser tomadas para que a urbanização não ocorra em detrimento da qualidade de vida nos centros urbanos, buscando sempre uma forma de minimizar as alterações e os impactos provenientes das alterações de paisagem nas cidades.

\section{AGRADECIMENTOS}

Os autores agradecem a Fundação de Amparo á Pesquisa do Estado de São Paulo pelo apoio recebido em projeto na linha de políticas públicas para realização desta pesquisa.

\section{REFERÊNCIAS BIBLIOGRÁFICAS}

CONGALTON, R.G. Accuracy assessment and validation of remotely sensed and other spatial information. International Journal of Wildland Fire, v. 10, p.321-328, 2001.

COUTO, H.T.Z.; VETORAZZI, C.A.; FERRAZ, S.F.B.; POMPERMAYER NETO, P. Airborne videography as a data source for decision making process in agriculture. In: International Conference on Geospatial Information In Agriculture and Forest, 2., 2000. Proceedings... Lake Buena Vista: ERIM, 2000. Artigos, p. 459-4651.

GÓMEZ, F.; GIL, L.; JABALOYES, J. Experimental investigation on the thermal comfort in the city: relationship with the green areas, interaction with the urban microclimate. Building and Environment, v. 39, p. 1077-1086, 2004.

GREY, G.W.; DENEKE, F.J. Urban forestry. New York, John Wiley, 1978, 279p.

IBGE - Instituto Brasileiro de Geografia e Estatística. STATCART: base de informações por setor censitário, Piracicaba, SP - censo demográfico 2000. Rio de Janeiro, 2002. 1 - CD-ROM.

LANDIS, J.R.; KOCH, G.G. The measurement of observer agreement for categorical data. Biometrics, v. 33, n. 1, p. 159-174, 1977. 
MASMOUDI, S.; MAZOUZ, S. Relation of geometry, vegetation and thermal comfort around buildings in urban settings, the case of hot arid regions. Energy and Buildings, v. 36, p. 710-719, 2004.

MOREIRA, M. A. Fundamentos do sensoriamento remoto e metodologias de aplicação. Viçosa: UFV, 2003. 307 p.

NOWAK, D .J.; DWYER, J. F. Understanding the benefits and costs of urban forest ecosystems. In: Kluwer Academic/Plenum Publishers. Handbook of urban and community forestry in the Northeast, New York, 2000, pp.11-22.

PAIVA, H.N; GONÇALVES, W. Florestas urbanas: Planejamento para uma melhoria da qualidade de vida. 1 ed. Viçosa: Aprenda Fácil, 2002. 177 p. (Série Arborização Urbana, n. 2).

PICOT, X. Thermal comfort in urban spaces: impact of vegetation growth case study: Piazza della Scienza, Milan, Italy. Energy and Buildings, v. 36, p. 329-334, 2004.

SACAMANO, P.L.; MCPHERSON, E.G.; MYHRE, J.; STANKOVICH, M.; Weih, R.C. Describing urban forest cover: an evaluation of airborne videography. Journal of Forestry, v. 93, p. 43-48, 1995.

SHASUA-BAR, L.; HOFFMAN, M. E. Geometry and orientation aspects in passive cooling of canyon streets with trees. Energy and Buildings, v. 35, p. 61-68, 2003.

SILVA FILHO, D. F. Aplicação de videografia aérea multiespectral na avaliação de floresta urbana. 2004. 88 p. Tese (Doutorado em Agronomia) - Universidade Estadual Paulista Julio de Mesquita Filho, Jaboticabal.

SILVA FILHO, D.F.; PIVETTA, K.F.L.; COUTO, H.T.Z.; POLIZEL, J.L. Indicadores de floresta urbana a partir de imagens aéreas multiespectrais de alta resolução. Scientia Forestalis, n. 67, p. 88-100, 2005.

WILLMERS, F. Effects of vegetation on urban climate and buildings. Energy and Buildings, v. 15-16, p. 507-514, 1990/1991. 
YAMAMOTO, M. A.; SCHIMIDT, R. O. L.; COUTO, H. T. Z.; SILVA FILHO, D. F. Árvores urbanas. 2004. Disponível em: <http://lmq.esalq.usp.br/ dfsilva/arvores_urbanas.pdf>. Acesso em 7 fev 2007. 